OPEN

SUBJECT AREAS:

PALAEOMAGNETISM

PALAEOCLIMATE

Received

25 July 2014

Accepted

11 December 2014

Published

23 January 2015

Correspondence and requests for materials should be addressed to

C.D. (cldeng@mail. iggcas.ac.cn)

\section{Insolation driven biomagnetic response to the Holocene Warm Period in semi-arid East Asia}

\author{
Suzhen Liv' ${ }^{1,2}$, Chenglong Deng ${ }^{1}$, Jule Xiao ${ }^{3}$, Jinhua Li ${ }^{4}$, Greig A. Paterson ${ }^{4}$, Liao Chang ${ }^{5}$, Liang Yi' \\ Huafeng Qin', Yongxin Pan ${ }^{4} \&$ Rixiang Zhu'
}

'State Key Laboratory of Lithospheric Evolution, Institute of Geology and Geophysics, Chinese Academy of Sciences, Beijing 100029, China, ${ }^{2}$ University of Chinese Academy of Sciences, Beijing 100049, China, ${ }^{3}$ Key Laboratory of Cenozoic Geology and Environment, Institute of Geology and Geophysics, Chinese Academy of Sciences, Beijing 100029, China, ${ }^{4}$ Key Laboratory of Earth and Planetary Physics, Institute of Geology and Geophysics, Chinese Academy of Sciences, Beijing 100029, China, ${ }^{5}$ Research School of Earth Sciences, The Australian National University, Canberra, ACT 0200, Australia.

The Holocene Warm Period (HWP) provides valuable insights into the climate system and biotic responses to environmental variability and thus serves as an excellent analogue for future global climate changes. Here we document, for the first time, that warm and wet HWP conditions were highly favourable for magnetofossil proliferation in the semi-arid Asian interior. The pronounced increase of magnetofossil concentrations at $\sim 9.8 \mathrm{ka}$ and decrease at $\sim 5.9 \mathrm{ka}$ in Dali Lake coincided respectively with the onset and termination of the HWP, and are respectively linked to increased nutrient supply due to postglacial warming and poor nutrition due to drying at $\sim 6 \mathrm{ka}$ in the Asian interior. The two-stage transition at $\sim 7.7 \mathrm{ka}$ correlates well with increased organic carbon in middle HWP and suggests that improved climate conditions, leading to high quality nutrient influx, fostered magnetofossil proliferation. Our findings represent an excellent lake record in which magnetofossil abundance is, through nutrient availability, controlled by insolation driven climate changes.

M agnetofossils, which are geologically preserved magnetic minerals produced by magnetotactic bacteria (MTB), have been proposed as distinctive environmental indicators ${ }^{1}$. Responses of MTB to palaeoenvironmental variations have been documented in various sedimentary settings, such as pelagic marine carbonates $^{2,3}$ and haemipelagic marine $e^{4-6}$ and lake sediments ${ }^{7}$.

Hyperthermal events in geological times, such as Palaeocene-Eocene Thermal Maximum, Early Eocene Climate Optimum, Mid-Miocene Climate Optimum, and Holocene Warm Period (HWP), are believed to have profoundly changed global and/or regional hydrologic cycles, and thus significantly reshape sedimentary and biological processes in marine and terrestrial environments ${ }^{8,9}$. In particular, links between magnetofossil characteristics and hyperthermal events (mainly Palaeocene-Eocene Thermal Maximum) have been suggested based on several lines of evidence from ferromagnetic resonance, transmission electron microscope (TEM) and rock magnetism ${ }^{3-5,6,9-10}$.

The HWP is of particular interest to the palaeoclimate communities due to its significance for understanding the background of natural variability underlying anthropogenic climate chang $\mathrm{e}^{11}$. It is therefore essential to develop new comprehensive records of how the HWP impacted environmental and biological systems and to reconstruct the details of climate changes during this time period.

Here we report the first robust magnetofossil sequence through the HWP (9.8-5.9 ka) in lake sediments from the Asian interior. We investigated the magnetic properties of an $8.5-\mathrm{m}$ Holocene lake sediment core from Dali Lake, Inner Mongolia, northern China (Fig. 1), in which the magnetic properties are controlled by biogenic and detrital magnetic minerals. We produce a $0.82 \mathrm{~m}$ magnetofossil sequence, which spans the 3.9kyr HWP with a resolution of $\sim 48$ years. Our results document the first biomagnetic record of HWP climate variability at the northern limit of the East Asian summer monsoon. The biomagnetic response to the HWP is unambiguously demonstrated using a combination of magnetic measurements (Figs. 2-4) and TEM analyses (Fig. 5). 


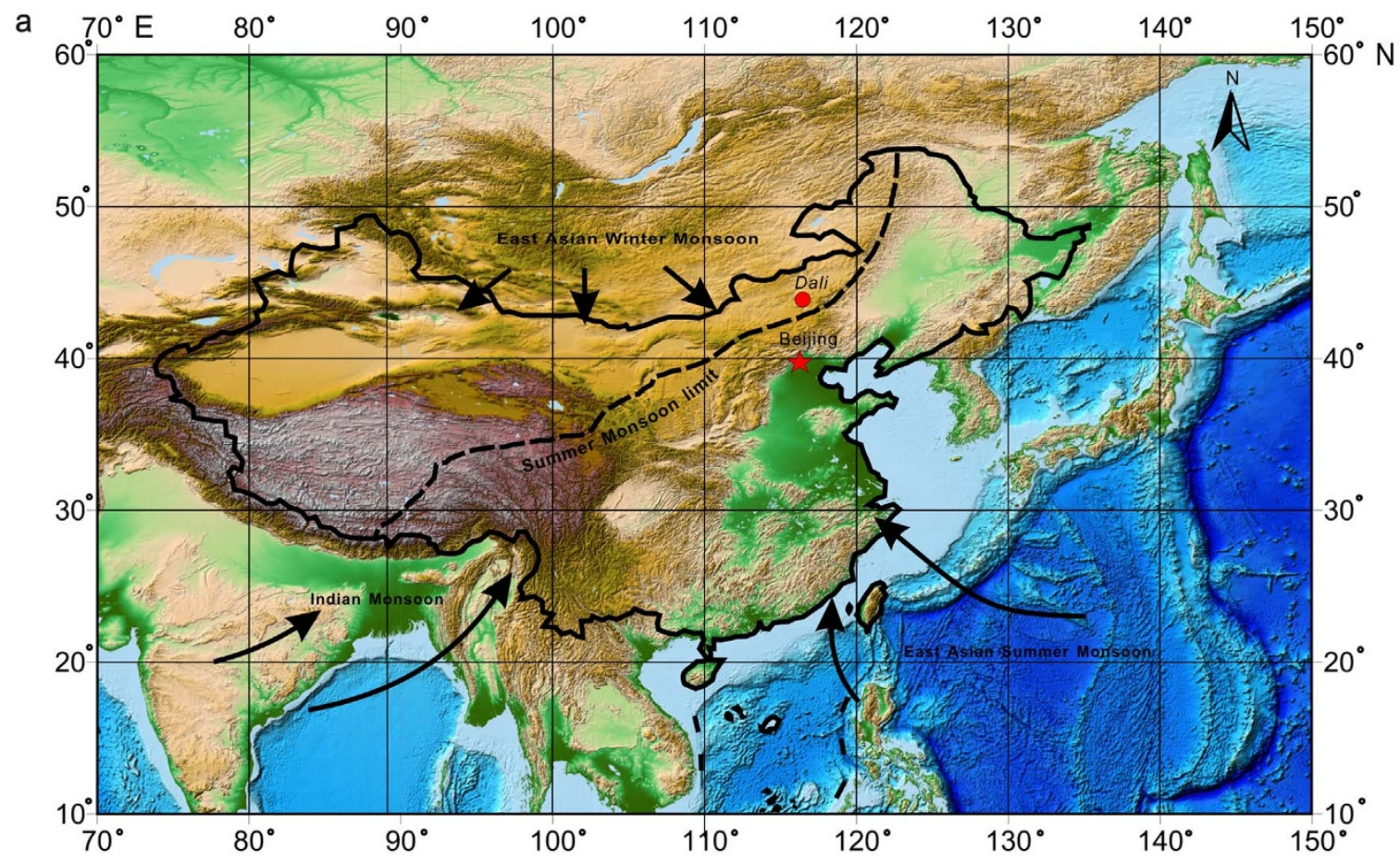

b
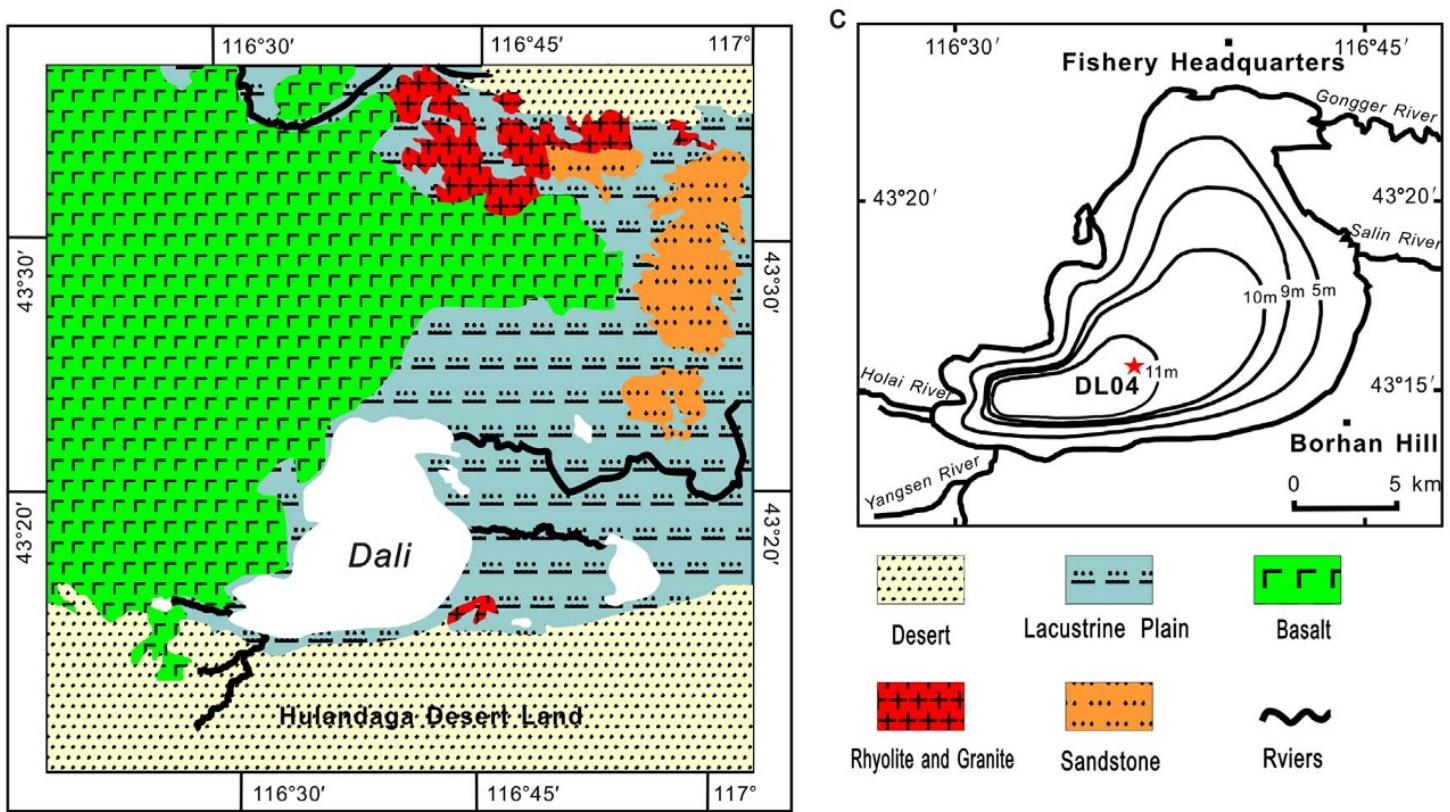

Figure $1 \mid$ Maps of the setting of Dali Lake and the coring site. (a) Regional map with atmospheric circulation (black arrows): the East Asian summer monsoon, East Asian winter monsoon and Indian monsoon. Boundary (black dashed line): modern summer monsoon limit. (b) Geological setting of Dali Lake. (c) Bathymetric map of Dali Lake with the four main inflowing rivers. The red star represents the location of sediment core DL04.

Part (a) is generated using the open and free software DIVA-GIS 7.5 (http://www.diva-gis.org/).

\section{Results}

Rock magnetism. The S-ratio, which is a composition-dependent parameter, is defined as the ratio of isothermal remanent magnetization acquired at $-0.3 \mathrm{~T}\left(\mathrm{IRM}_{-0.3 \mathrm{~T}}\right)$ to saturation IRM acquired at $1 \mathrm{~T}\left(\mathrm{IRM}_{1 \mathrm{~T}} \text {, hereinafter termed SIRM) }\right)^{12}$, has high values (generally above 0.9) throughout the studied core (Fig. 2a). This indicates the dominance of low-coercivity minerals (magnetite and/or maghaemite). Up-section, S-ratio generally decreases after the HWP, which indicates an increasing contribution of high-coercivity minerals (most likely aeolian haematite).
Low-field mass-specific magnetic susceptibility $(\chi)$, anhysteretic remanent magnetization (ARM) and SIRM, which are concentration-dependent parameters, have similar variations throughout the core (Fig. 2b-d). The HWP interval has notably high $\chi$, ARM and SIRM values, which is due to the contribution from biogenic magnetite (i.e., magnetofossils), as indicated by analysis of first-order reversal curve (FORC) ${ }^{13-16}$ diagrams (Fig. 4) and TEM observations (Fig. 5). $\chi$, ARM and SIRM for the pre-HWP sediments exhibit an up-section increasing trend, while the post-HWP sediments have nearly constant values, with the exception of isolated peaks. 


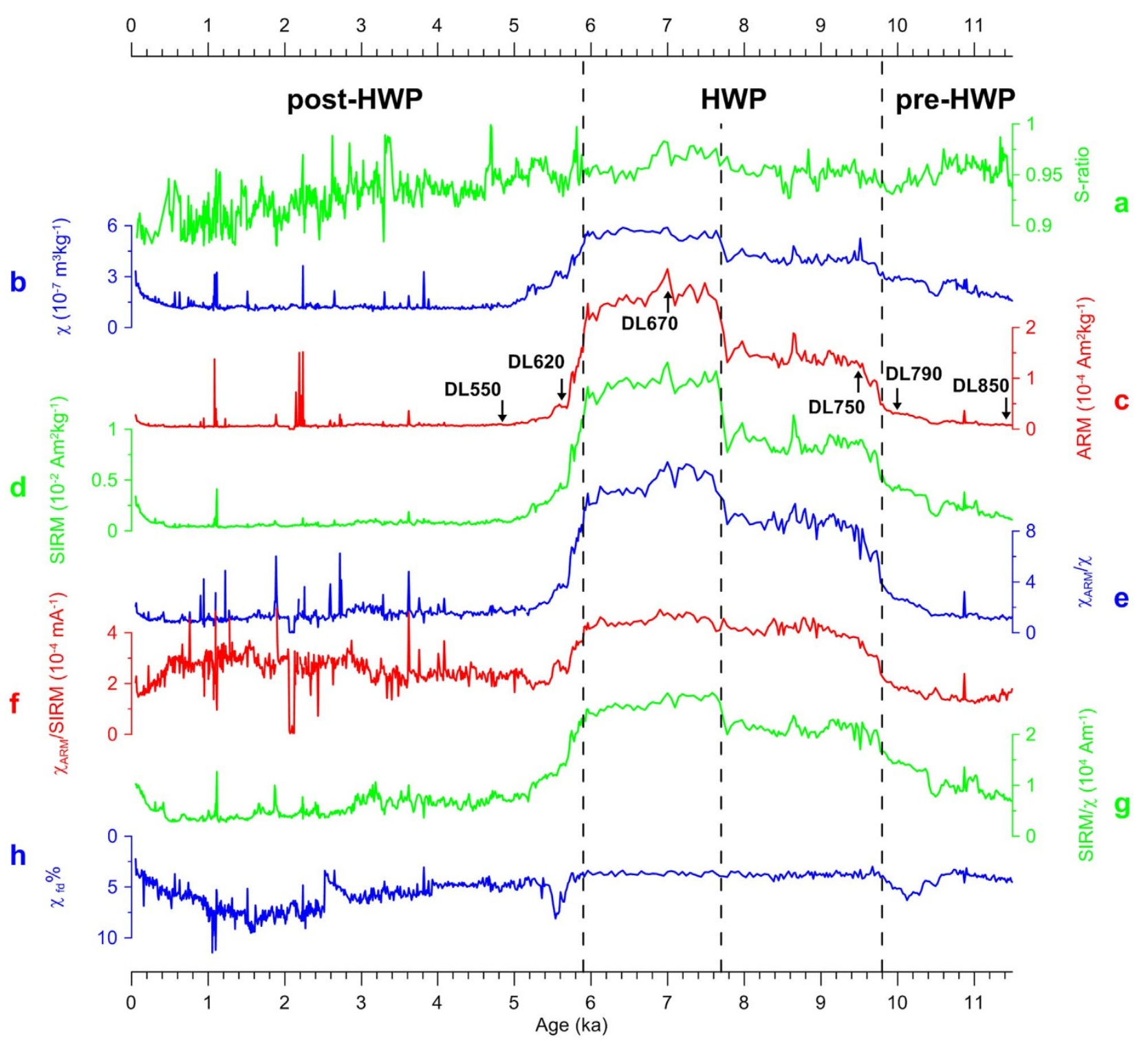

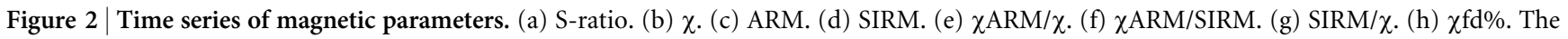
sequence is divided into three units (pre-HWP, HWP and post-HWP), see text for details. Positions of representative samples are shown in (c).

Importantly, the three parameters undergo a distinct two-stepped transition during the HWP. Specifically, early HWP (before $7.7 \mathrm{ka}$ ) values are generally low, but at $7.7 \mathrm{ka}$ there is a noticeable increase, which is followed by a pronounced decrease in $\chi$, ARM and SIRM at $\sim 5.9 \mathrm{ka}$, the HWP termination.

Grain-size-dependent magnetic parameters $\chi_{\text {ARM }} / \chi\left(\chi_{\text {ARM }}\right.$ was determined from the ARM intensity, divided by the bias field strength), $\chi_{\mathrm{ARM}} / \mathrm{SIRM}$ and SIRM $/ \chi$ have similar variations throughout the core (Fig. 2e-g). The HWP sediments have higher values of these parameters than the pre- and post-HWP sediments, which indicates finer magnetic grain sizes in the HWP sediments compared with coarser grain sizes in the pre- and post-HWP sediments. A gradual up-section increase in $\chi_{\mathrm{ARM}} / \chi, \chi_{\mathrm{ARM}} / \mathrm{SIRM}$ and SIRM $/ \chi$ for the pre-HWP sediments is observed and indicates an up-section magnetic grain size decrease during the pre-HWP. Similar to the concentration-dependent parameters, there is also a rapid drop in these grain-size-dependent magnetic parameters at $\sim 5.9 \mathrm{ka}$, which indicates a sudden decrease in fine-grained biogenic magnetite and an increase in coarse-grained detrital magnetite particles. A marked increase in $\chi_{\mathrm{ARM}} / \chi$ and SIRM $/ \chi$ is also discernable at $\sim 7.7 \mathrm{ka}$, which suggests a significant increase in fine-grained ferrimagnetic biogenic magnetite particles.

Percentage of frequency-dependent magnetic susceptibility $\left(\chi_{\mathrm{fd}} \%\right)$ has a nearly constantly low value of $\sim 4 \%$ in the HWP sediments, but it has variable and higher values in the pre- and post-HWP sediments (Fig. 2h). This indicates an enrichment of superparamagnetic (SP) particles near the SD (single domain)/SP threshold size in the preand post-HWP sediments.

A bi-logarithmic plot of $\chi_{\mathrm{ARM}} / \chi_{\mathrm{fd}}\left(\chi_{\mathrm{fd}}\right.$ is frequency-dependent magnetic susceptibility) versus $\chi_{\mathrm{ARM}} / \chi$ (Fig. 3 ) aids in distinguishing between samples rich in biogenic magnetite and those rich in ferrimagnetic minerals derived from eroding soils ${ }^{17}$. Data for the HWP samples cluster in the upper right-hand corner of the plot and are characterized by high values of both $\chi_{\mathrm{ARM}} / \chi_{\mathrm{fd}}$ and $\chi_{\mathrm{ARM}} / \chi$, which indicates a dominance of SD magnetite (magnetofossils). In contrast, data for the pre- and post-HWP samples cluster in the lower lefthand corner of the plot. This is likely due to significant contributions from SP particles that have high $\chi$ and $\chi_{\mathrm{fd}} \%$, but low ARM values. The bi-logarithmic plot results, together with the correlation of concentration-dependant magnetic parameters (Supplementary Fig. 1), 


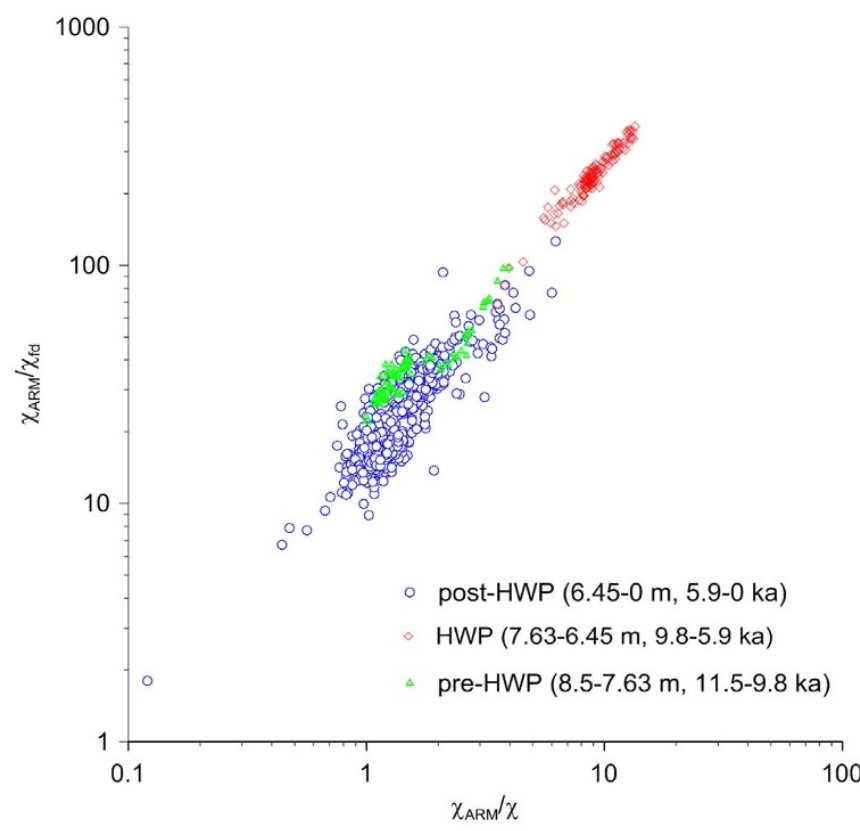

Figure $3 \mid$ Bi-logarithmic plot of $\chi_{\mathrm{ARM}} / \chi_{\mathrm{fd}}$ versus $\chi_{\mathrm{ARM}} / \chi$. Samples clustered in the upper right-hand-side of the plot are indicative of biogenic magnetite, while samples in the lower left-hand-side are indicative of detrital input from soil erosion ${ }^{17}$.

indicate different origins of magnetic minerals in the HWP samples compared with the pre- and post-HWP samples, which is confirmed by detailed rock magnetic and TEM analyses (Figs. 4,5).

Mineral magnetic properties. Representative samples (DL550, 620, $670,750,790$, and 850) from the core were selected for further magnetic analyses to identify the origin of the magnetic signal (Fig. 4, Supplementary Fig. 2 and Table 1). Hysteresis measurements generally indicate the dominance of low-coercivity ferrimagnetic minerals (Fig. $4 \mathrm{a}-\mathrm{c}$ ). Although coercivities of remanence $\left(B_{\mathrm{cr}}\right)$ are comparable for all samples, the HWP samples generally have higher coercivities $\left(B_{c}\right)$ than those for pre- and post-HWP samples (e.g., $\sim 20$ to $\sim 25 \mathrm{mT}$ for the former, but $\sim 10 \mathrm{mT}$ for the latter; Supplementary Table 1). This difference may be due to the higher fraction of fine SP and coarser-grained magnetic particles within preand post-HWP samples compared with HWP samples, which will decrease the bulk $B_{\mathrm{c}}$, but affect $B_{\mathrm{cr}}$ less. This is confirmed by $\chi_{\mathrm{fd}} \%$ values (Fig. $2 \mathrm{~h}$ ) and low-temperature magnetic measurements (Fig. 4d-f).

The sharp IRM decrease at $\sim 100 \mathrm{~K}$ in SIRM $_{20 \mathrm{~K} \_2.5 \mathrm{~T}}$ curves (Fig. 4e) for sample DL670, known as the Verwey transition ${ }^{18}$, demonstrates the presence of magnetite. The observed Verwey transition temperatures $\left(T_{\mathrm{v}}=95-110 \mathrm{~K}\right)$ are comparable with $T_{\mathrm{v}}$ for SD magnetite produced by modern $\mathrm{MTB}^{19,20}$, but are lower than for stoichiometric coarse-grained magnetite $(\approx 120 \mathrm{~K})$. In contrast, Verwey transition signals are not as strongly apparent for pre- and post-HWP samples (Fig. 4d,f), which can be explained by the presence of large amounts of SP magnetite or/and partial magnetite oxidation ${ }^{21}$.

Variable FORC diagrams are observed (Fig. 4g-k). For pre- and post-HWP samples, the FORC distribution peaks at $B_{\mathrm{c}} \approx 9 \mathrm{mT}$ (Fig. 4g,i). The inner contours close around the peak, while the outer contours remain open and intersect the $y$-axis, but do not diverge. This is indicative of pseudo-single domain (PSD) particles ${ }^{13,16}$. FORC distributions for HWP samples peak at $B_{\mathrm{c}} \approx 38 \mathrm{mT}$ with concentric contours (Fig. 4h) and horizontal elongation with little vertical spread, which indicates a dominance of high-coercivity non-interacting uniaxial SD particles. High-resolution FORC diagrams for HWP samples (Fig. 4j,k) yield a sharp central ridge that is character- istic of an assemblage of non-interacting SD particles. This is a strong indication of magnetofossils produced by $\mathrm{MTB}^{14,15}$.

TEM analyses. To unambiguously detect magnetofossils within the HWP sediments, a magnetic extract was taken from sample DL670 and was analyzed with TEM techniques. Both TEM and HAADF (high angle annular dark field)-STEM (scanning TEM) observations reveal euhedral grains with diverse sizes and morphologies (Fig. 5). These particles range from $\sim 20 \mathrm{~nm}$ to $\sim 100 \mathrm{~nm}$ in size and have cubo-octahedral, prismatic, and bullet shapes, which are morphologically comparable with magnetites produced by modern MTB (e.g., ref. 22). HAADF-STEM-XEDS (X-ray energy dispersive spectra) mapping indicates that these euhedral particles are rich in iron and oxygen (Supplementary Fig. 3), which suggests that they are Fe oxides. High-resolution TEM (HRTEM) observations further indicate that these nanocrystals have the same crystal structure as magnetite. Overall, comprehensive TEM analyses provide strong morphological, chemical and structural evidence for a biogenic origin of magnetite within the HWP sample.

\section{Discussion}

Combined rock magnetic and TEM analysis reveals that the HWP sediments are magnetically dominated by magnetofossils. Magnetofossils that survive in geological records benefit from both magnetosome production and preservation. Magnetofossil concentration in geological record, therefore, may depend mainly on magnetosome production $^{10}$ or preservation ${ }^{7}$ or both ${ }^{5}$. In this study, however, dissolution of biogenic magnetite is not likely to be a major factor. The presence of large amounts of SP particles (Fig. 2h) and absence of iron sulphides (as indicated by the absence of sulphide oxidation during thermomagnetic analyses; Supplementary Fig. 2) in the post-HWP sediments suggest the absence of reductive dissolution in Dali Lake sediments. The relatively high abundance of magnetofossils in Dali Lake is, therefore, a result of MTB proliferation and biomineralization rather than being an artifact of preservation. It is a widely held view that MTB live in regions with strong vertical chemical gradients near the oxic-anoxic interface ${ }^{23}$. MTB populations cultured under a wide range of oxygenation conditions ${ }^{24}$ and magnetofossils found in sediments that were never anoxic ${ }^{25}$, however, indicate that such chemically stratified environments are not necessarily required for MTB population to flourish. Magnetosomes, due to their small particle size, tend to dissolve when buried under anoxic conditions $^{1}$. In Dali Lake, MTB appear to have lived in a microaerobic environment and their magnetosomes were subsequently buried as magnetofossils in suboxic, but never anoxic conditions ${ }^{2}$.

Proliferation of MTB in Dali Lake sediments coincides with a period with warm and wet conditions due to increased insolation during the HWP (Fig. 6). High temperature and abundant precipitation during the HWP would have resulted in increased surface runoff and stronger chemical weathering. This would have enhanced catchment erosion and, therefore, increased the input of iron-rich basalt and terrestrial bio-matter into the lake. Increased surface runoff, evidenced by higher total organic carbon (TOC) and higher lake levels during the HWP ${ }^{26,27}$, would bring abundant nutrients including bioavailable iron and organic carbon into the lake for MTB biomineralization $^{2}$. Therefore, magnetofossil abundance can be attributed to increased nutrient delivery into the lake in association with insolation-driven warm and wet HWP conditions.

The pronounced increase in ferrimagnetic mineral concentration and upward fining magnetic grain size at $\sim 9.8 \mathrm{ka}$ are caused by the transition from detrital magnetite derived from the catchment to biogenic magnetofossils produced within the lake. This increase corresponds to the onset of the HWP, which coincided with peak insolation at $65^{\circ} \mathrm{N}$ (ref. 28) (Fig. 6).

The rapid shift of magnetic minerals from magnetofossils to detrital magnetite at $\sim 5.9$ ka corresponds to the sudden termination 
DL650 at $6.6 \mathrm{~m}, 4.69 \mathrm{ka} \mathrm{BP}$ (post-HWP)
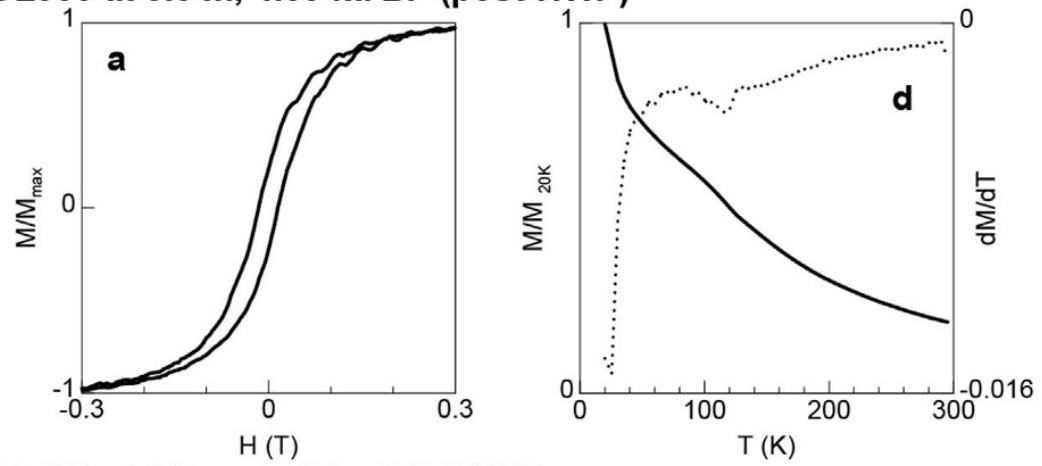

DL670 at $6.7 \mathrm{~m}, 6.96 \mathrm{ka} B P(\mathrm{HWP})$
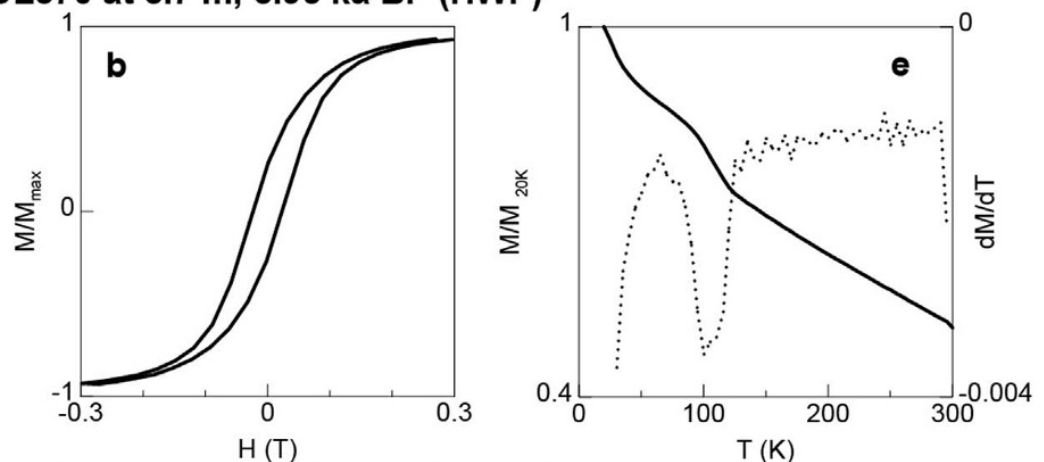

DL850 at $8.6 \mathrm{~m}, 11.46 \mathrm{ka}$ BP (pre-HWP)
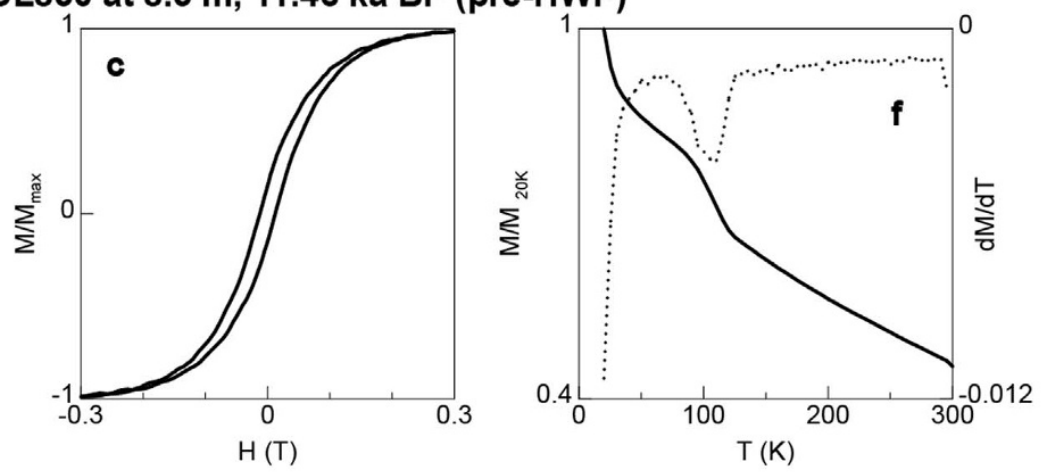
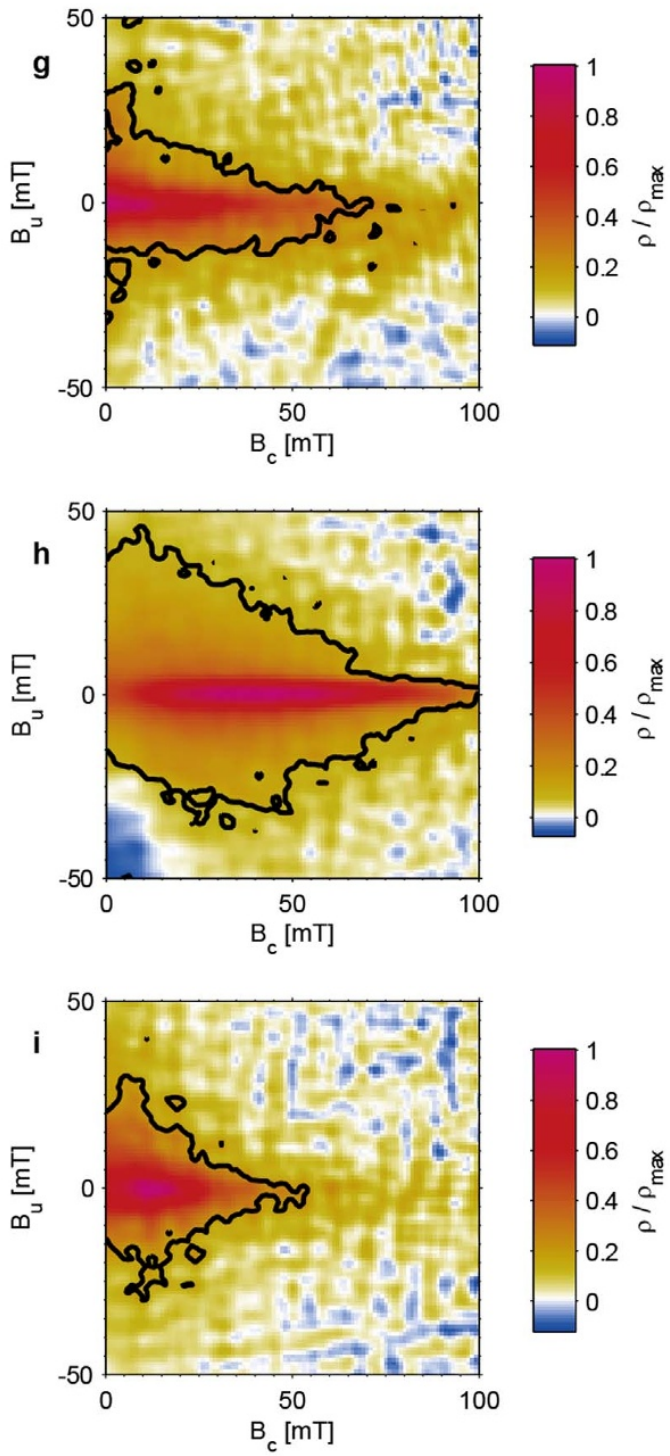
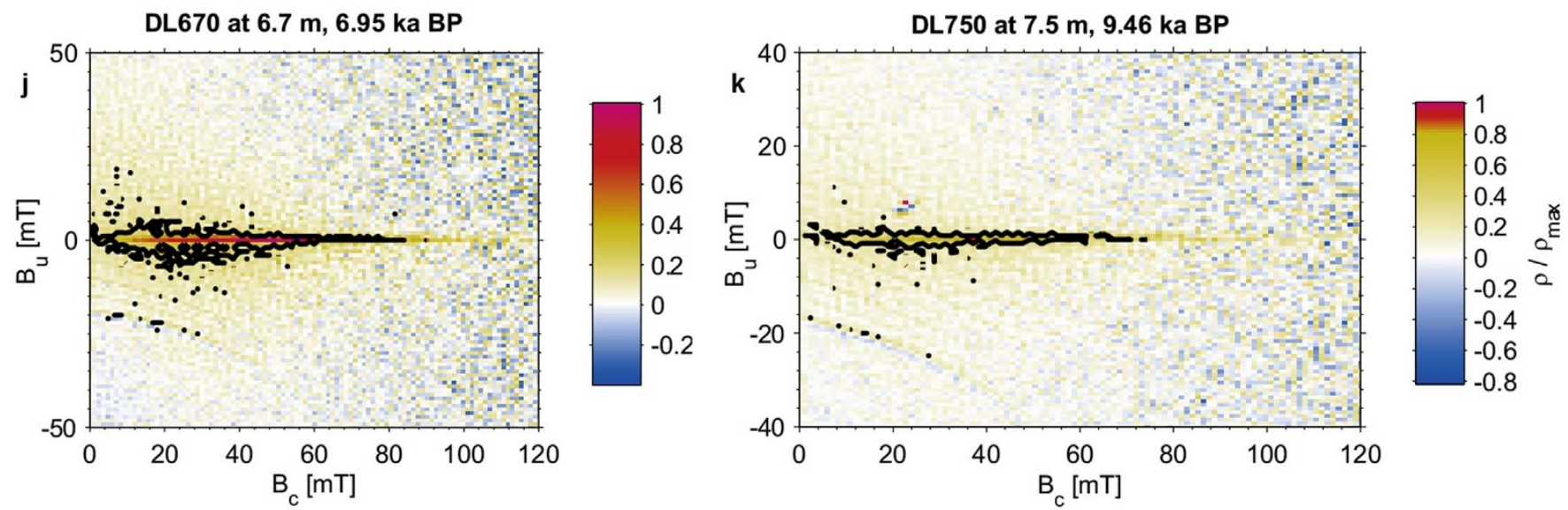

Figure $4 \mid$ Representative rock magnetic results. Samples DL670 and DL750 represent the HWP sediments dominated by biogenic magnetite, while samples DL550 and DL850 represent sediments magnetically dominated by detrital magnetite. $(\mathrm{a}-\mathrm{c})$ Hysteresis loops after paramagnetic slope correction. To get higher signal-to-noise ratios, three measurements were repeated and averaged. (d-f) Solid lines represent thermal demagnetization curves of a lowtemperature IRM imparted at $20 \mathrm{~K}$ in a $2.5 \mathrm{~T}$ field after ZFC treatment. Moments are normalized by the value at $20 \mathrm{~K}$. The dotted lines represent the first derivative, $\mathrm{dM} / \mathrm{dT}$, of the warming curve after ZFC treatment. ( $\mathrm{g}-\mathrm{i}$ ) Low-resolution FORC diagrams, measured with $\delta \mathrm{B}=0.876 \mathrm{mT}$ and calculated with $\mathrm{SF}=4$. ( $\mathrm{j}-\mathrm{k})$ High-resolution FORC diagrams of the HWP samples, measured with $\delta \mathrm{B}=0.4 \mathrm{mT}$ and calculated with $\mathrm{SF}=4$. The thick contour lines indicate the regions of the FORC distribution that are significant at the 0.05 level $^{37}$. The diagrams in ( $\left.\mathrm{j}-\mathrm{k}\right)$ are averages of three FORC runs. 

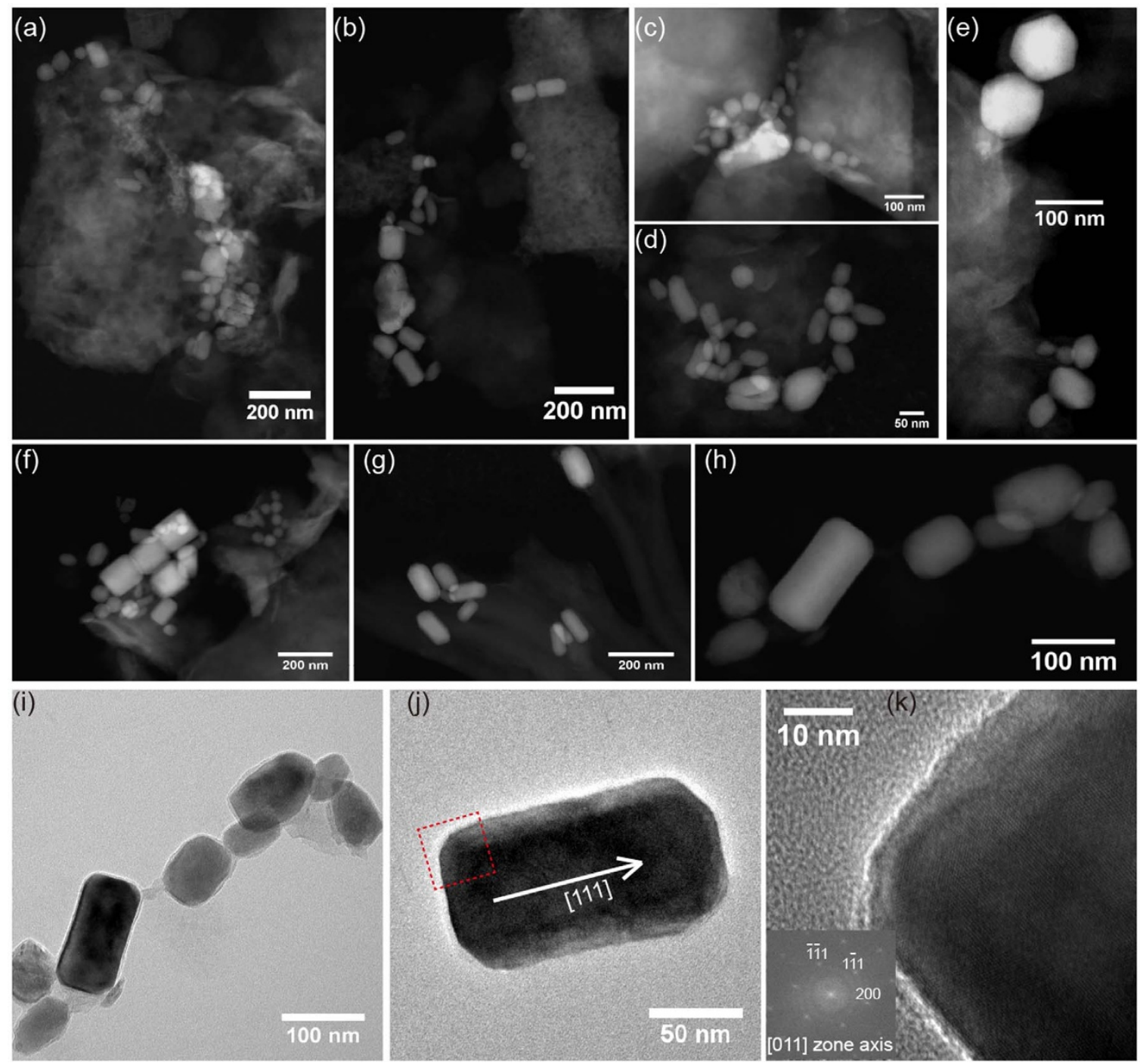

Figure $5 \mid$ TEM analyses of magnetofossils from the HWP sediments (DL670). (a-h) HAADF-STEM images of magnetofossils. HAADF-STEM allows Z-contrast imaging, which is suitable for magnetofossil identification based on morphological features and contrast with the surrounding matrix.

(i) Bright-field TEM image of magnetofossils in (h). (j) HRTEM image of a typical prismatic magnetite recorded from [011] zone axis. (k) Close-up image of the area indicated by the red dashed square in (j). The corresponding fast Fourier transform (FFT) pattern is indexed and shown in the inset. HRTEM imaging and the FFT pattern indicate that this particle is elongated along the [111] direction of magnetite, which is consistent with cubo-octahedral magnetosomes ${ }^{22}$.

of the HWP, which, in turn, is linked to the rapid insolation decrease at $65^{\circ} \mathrm{N}$ (ref. 28) (Fig. 6). Decreased surface runoff during the cold and dry post-HWP period would have resulted in a decreased nutrient supply, which would have led to a decline in MTB population. Therefore, the rapid shift from biogenic to detrital dominance of magnetic minerals in Dali Lake during 6-5.7 ka is probably related to drying at $\sim 6 \mathrm{ka}$ in the Asian interior ${ }^{29}$. The $\sim 6 \mathrm{ka}$ drying marks the abrupt termination of the HWP in central Inner Mongolia. This finding, combined with previous observations from the northwestern Pacific ${ }^{29}$, North Atlantic ${ }^{30}$, West Africa ${ }^{31-33}$, America ${ }^{34}$ and South China ${ }^{35}$, further suggests the global nature of this abrupt climate shift.

On the basis of highly magnetic HWP sediments, the two-step biomagnetic signal before and after $\sim 7.7 \mathrm{ka}$ correlates well with inferred changes in the source of water flowing into the lake. Previous studies of total organic and inorganic carbon concentrations in Dali Lake indicate that water input during the early Holocene originated mostly from snow/ice melt with less catchment erosion and land-derived organic matter ${ }^{26}$. For the late HWP, however, Dali
Lake received water mostly from monsoonal precipitation. The warmer and wetter climate after $\sim 7.7 \mathrm{ka}$ would have brought more monsoonal rainfall, which have caused greater surface runoff from the catchment and allowed vegetation to thrive. Increased runoff would have brought higher quality nutrients into the lake. This further indicates that the two-stage biomagnetic behaviour (increase at $\sim 7.7 \mathrm{ka}$ ) reflects a biomagnetic response to increased nutrient delivery.

To summarize, high-resolution rock magnetic analyses of the DL04 sediment core from Dali Lake, northern China, reveal that the HWP sediments are magnetically dominated by magnetofossils derived from MTB magnetosomes. The abundance of magnetofossils reflects conditions during the HWP when favourable climate and associated improved nutrient supply, such as bioavailable iron and organic carbon, enhanced the ability of MTB to biomineralize magnetite. In contrast, magnetic minerals in the pre- and post-HWP sediments mainly consist of detrital minerals from catchment erosion of bedrock and soils. Absence of biogenic magnetite in intervals that preceded and succeeded the HWP could be attributed to low 


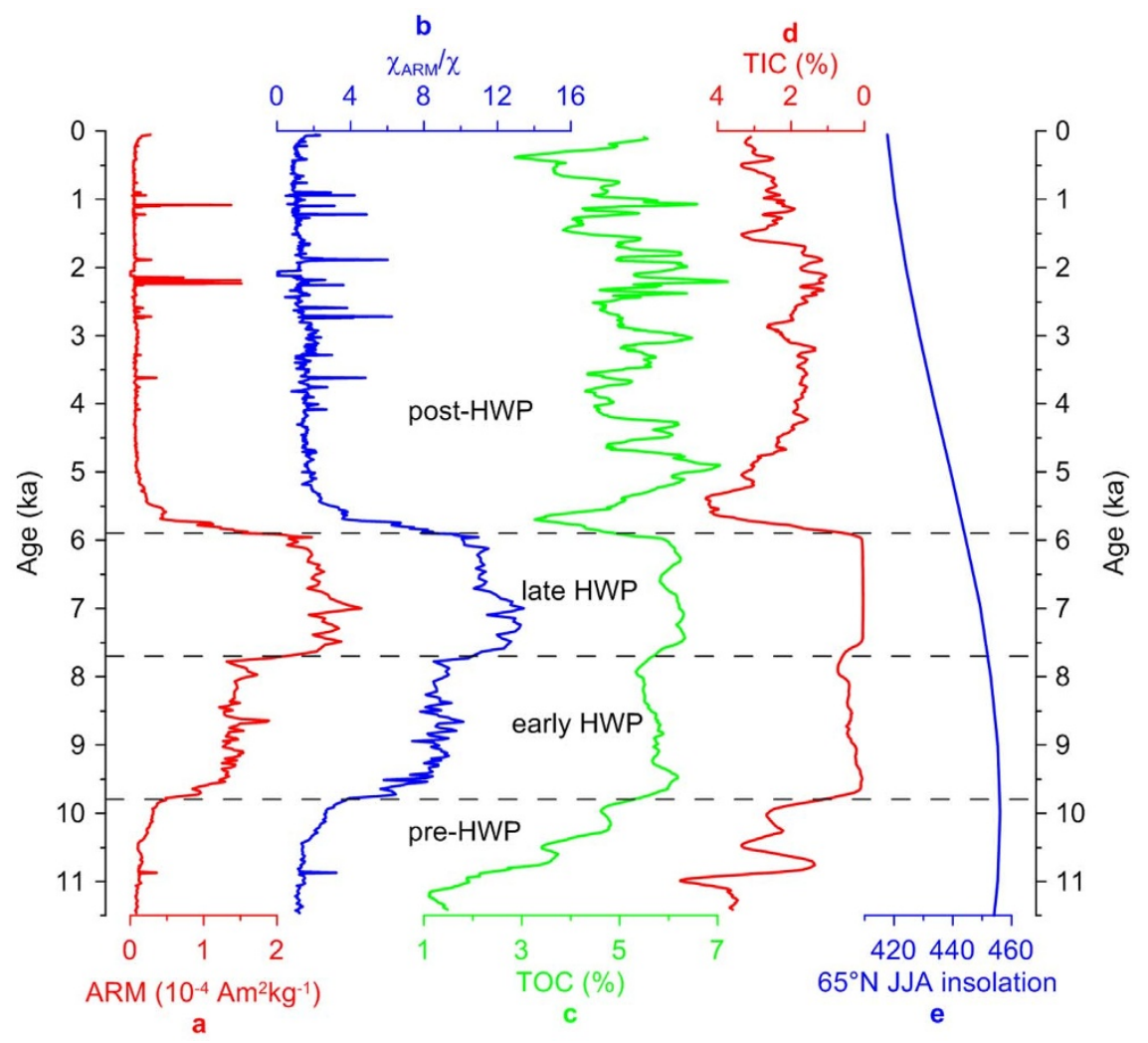

Figure 6 Comparison of magnetic mineral concentration (ARM) and magnetic grain size $\left(\chi_{\mathrm{ARM}} / \chi\right)$ with total organic carbon (TOC), total inorganic carbon (TIC) and the summer (June, July, August) average insolation computed for $65^{\circ} \mathrm{N}$ (ref. 28). High TOC and low TIC reflect high lake level (data from ref. 26). Note the reversed scale in (d). The black dashed lines separate the different time intervals (pre-, early, late and post-HWP).

nutrient flux under cold and dry conditions. The transition from detrital to biogenic magnetite at $\sim 9.8 \mathrm{ka}$ marked the onset of the HWP and is linked to postglacial warming, while the rapid shift from biogenic to detrital dominance of magnetite at $\sim 5.9$ ka marked the termination of the HWP and is linked to drying of the Asian interior at $\sim 6 \mathrm{ka}$. Enhanced proliferation of biogenic magnetite at $\sim 7.7 \mathrm{ka}$ corresponds to the inferred turning point at which water input into Dali Lake transfers from colder snow/ice melt to warmer monsoonal precipitation at $\sim 7.6 \mathrm{ka}$ (ref. 26 ). The shift from snow/ice covered to more exposed terrain in the catchment area of Dali Lake is likely to have resulted in an increased nutrient flux due to direct erosion of the catchment area by monsoonal precipitation, which resulted in further proliferation of MTB. Our biomagnetic record correlates well with changes in summer insolation at high northern latitudes, which reflects the response of biotic systems in semi-arid lakes to insolation-driven climate changes through magnetic mineral production and deposition.

\section{Methods}

Geology, sampling and chronology. Dali Lake $\left(43^{\circ} 13^{\prime}-23^{\prime} \mathrm{N}, 116^{\circ} 29^{\prime}-45^{\prime} \mathrm{E}\right)$, which is located in central Inner Mongolia at 1226 m.a.s.l., is an inland closed-basin lake structurally dammed by Pleistocene basalt (Fig. 1). This lake is located on the modern limit of the East Asian monsoon (Fig. 1a). Erosion in the surrounding catchment area is, therefore, likely to be influenced by monsoon variability. Pleistocene basaltic rocks surround the lake to the north and west. The E-W trending Hulandaga Desert Land lies to the south. Along the eastern shore are lacustrine plains (Fig. 1b). Because of its location in a semi-arid area with large evaporation and absence of draining rivers, Dali Lake is a soda brackish lake with salinity of up to $5.6 \%$ and $\mathrm{pH}$ of 9.6 (ref. 36). The lake has an area of $238 \mathrm{~km}^{2}$ and a maximum water depth of $11 \mathrm{~m}$. The lake floor has a steep slope near the shore and an almost flat bottom toward the centre (Fig. 1c)

The studied DL04 sediment core $\left(43^{\circ} 15.68^{\prime} \mathrm{N}, 116^{\circ} 36.26^{\prime} \mathrm{E}\right)$ was drilled at the depocenter, where there should be no significant water turnover. Drilling was performed in 2004 as described in ref. 26. Sediment cores were extracted to a depth beneath the lake floor of $12.57 \mathrm{~m}$. The cored sediments are composed of greenish- grey to blackish-grey homogeneous silts and silty clays ${ }^{26}$. The core was split and cut on site at $1-\mathrm{cm}$ intervals.

The chronology for core DL04 is based on linear interpolation between 15 accelerating mass spectra (AMS)-radiocarbon dates on bulk samples (Supplementary Table 2). The 12.57-m core covers the last $17.2 \mathrm{kyr}$. The upper $8.5 \mathrm{~m}$ of the DL0 4 core, which covers the last $11.5 \mathrm{kyr}$ (the Holocene), was used in this study. A total of 850 unoriented sediment samples were obtained from this interval.

Based on variations of magnetic parameters and the chronology from radiocarbon dating, we divide the sequence into three units: the pre-HWP unit (8.50-7.63 m, 11.5-9.8 ka), the HWP unit (7.63-6.45 $\mathrm{m}, 9.8-5.9 \mathrm{ka})$, and the post-HWP unit (6.45-0 m, 5.9-0 ka) (Fig. 2). The HWP sediments are dominated by biogenic magnetite, and the pre- and post-HWP sediments, by detrital magnetite.

Magnetic measurements. Magnetic measurements were carried out on all the 850 unoriented bulk sediment samples. The samples were first dried in vacuum and placed into standard $8 \mathrm{~cm}^{3}$ palaeomagnetic cubes. $\chi$ was measured using an AGICO MFK1-FA Multi-Frequency Kappabridge magnetic-susceptibility meter at frequencies of $976 \mathrm{~Hz}$ and $15616 \mathrm{~Hz}$. Two measures of frequency-dependent magnetic susceptibility $\left(\chi_{\mathrm{fd}}\right.$, defined as $\chi_{976 \mathrm{~Hz}}-\chi_{15616 \mathrm{~Hz}}$, and $\chi_{\mathrm{fd}} \%$, defined as $\left(\chi_{976 \mathrm{~Hz}}\right.$ $\left.-\chi_{15616 \mathrm{~Hz}}\right) / \chi_{976 \mathrm{~Hz}} \times 100 \%$ ) were calculated from these measurements. $\chi_{\mathrm{fd}} \%$ was used to identify particles close to the SP/SD transition. ARM was imparted using a peak alternating field (AF) of $100 \mathrm{mT}$ and a direct bias field of $0.05 \mathrm{mT}$ using a $2-\mathrm{G}$ Enterprises SQUID magnetometer with inline AF coil. IRM was induced with a 2-G Enterprises model 660 pulse magnetizer successively in pulsed fields of $1 \mathrm{~T}$ and $0.3 \mathrm{~T}$. The S-ratio ${ }^{12}$ was determined to estimate the relative contributions of lowcoercivity magnetic minerals (e.g., magnetite, maghaemite, and greigite) versus highcoercivity magnetic minerals (e.g., haematite and goethite). All remanence measurements were measured using the $2-\mathrm{G}$ magnetometer.

Magnetic properties of representative samples. Low-temperature magnetic measurements were performed on a Quantum Design Magnetic Property Measurement System (MPMS-XL). Samples were first cooled from $300 \mathrm{~K}$ to $20 \mathrm{~K}$ in zero field (ZFC). At $20 \mathrm{~K}$ an SIRM was imparted with a $2.5 \mathrm{~T}$ field (hereafter termed $\mathrm{SIRM}_{20 \mathrm{~K} \_2.5 \mathrm{~T}}$ ) and the remanence was measured during zero field warming to $300 \mathrm{~K}$. $T_{\mathrm{v}}$ of magnetite is defined as the temperature of the minimum in the first derivative of the ZFC curve.

Hysteresis loops, IRM acquisition, back-field demagnetization of SIRM, and FORCs (Fig. 4) were measured on a Princeton Measurements Corporation MicroMag 3900 vibrating sample magnetometer (VSM) up to a maximum field of 1.5 T. FORC diagrams were produced using the FORCme software ${ }^{37}$. Two selected samples with 
FORC distributions typical of non-interacting SD assemblages of biogenic magnetite (Fig. 4j,k) were further analyzed following the high-resolution FORC protocol described in ref. 14. To improve the signal-to-noise ratio of FORC diagrams, three FORC measurements were repeated and stacked. All diagrams were constructed using a smoothing factor of 4 .

TEM analysis. For TEM observations, magnetic extracts were obtained from bulk sediments by stirring the mortared sediment in a small volume of distilled water before thoroughly dispersing by ultrasonication. The magnetic particles were then extracted with a magnetic finger. To concentrate and purify the magnetic components, the extraction procedure was repeated at least five times. TEM experiments were carried out on a JEOL-2100F microscope operating at $200 \mathrm{kV}$, equipped with a field emission gun, an ultra-high-resolution (UHR) pole piece, a Gatan energy filter GIF 200, a JEOL detector with an ultrathin window allowing detection of light elements, and a STEM device, which allows Z-contrast imaging in HAADF mode. Compositional mapping was acquired by performing XEDS analysis in the STEM mode.

1. Kopp, R. E. \& Kirschvink, J. L. The identification and biogeochemical interpretation of fossil magnetotactic bacteria. Earth-Sci. Rev. 86, 42-61, doi:10.1016/j.earscirev.2007.08.001 (2008).

2. Roberts, A. P. et al. Magnetotactic bacterial abundance in pelagic marine environments is limited by organic carbon flux and availability of dissolved iron. Earth Planet. Sci. Lett. 310, 441-452, doi:10.1016/j.epsl.2011.08.011 (2011).

3. Larrasoaña, J. C. et al. Magnetotactic bacterial response to Antarctic dust supply during the Palaeocene-Eocene thermal maximum. Earth Planet. Sci. Lett. 333334, 122-133, doi:10.1016/j.epsl.2012.04.003 (2012).

4. Kopp, R. E. et al. An Appalachian Amazon? Magnetofossil evidence for the development of a tropical river-like system in the mid-Atlantic United States during the Paleocene-Eocene thermal maximum. Paleoceanography 24, PA4211, doi:10.1029/2009PA001783 (2009).

5. Kopp, R. E. et al. Magnetofossil spike during the Paleocene-Eocene thermal maximum: Ferromagnetic resonance, rock magnetic, and electron microscopy evidence from Ancora, New Jersey, United States. Paleoceanography 22, PA4103, doi:10.1029/2007PA001473 (2007)

6. Lippert, P. C. \& Zachos, J. C. A biogenic origin for anomalous fine-grained magnetic material at the Paleocene-Eocene boundary at Wilson Lake, New Jersey. Paleoceanography 22, PA4104, doi:10.1029/2007PA001471 (2007).

7. Kodama, K. P., Moeller, R. E., Bazylinski, D. A., Kopp, R. E. \& Chen, A. P. The mineral magnetic record of magnetofossils in recent lake sediments of Lake Ely, PA. Global Planet. Change 110, 350-363, doi:10.1016/j.gloplacha.2013.03.012 (2013).

8. Zachos, J., Pagani, M., Sloan, L., Thomas, E. \& Billups, K. Trends, rhythms, and aberrations in global climate 65 Ma to present. Science 292, 686-693, doi:10.1126/ science.1059412 (2001).

9. Schumann, D. et al. Gigantism in unique biogenic magnetite at the PaleoceneEocene Thermal Maximum. Proc. Natl. Acad. Sci. USA 105, 17648-17653, doi:10.1073/pnas.0803634105 (2008).

10. Chang, L. et al. Giant magnetofossils and hyperthermal events. Earth Planet. Sci. Lett. 351-352, 258-269, doi:10.1016/j.epsl.2012.07.031 (2012).

11. Mayewski, P. A. et al. Holocene climate variability. Quat. Res. 62, 243-255, doi:10.1016/j.yqres.2004.07.001 (2004).

12. King, J. W. \& Channell, J. E. T. Sedimentary magnetism, environmental magnetism, and magnetostratigraphy. Rev. Geophys. 29, 358-370 (1991).

13. Roberts, A. P., Pike, C. R. \& Verosub, K. L. First-order reversal curve diagrams: A new tool for characterizing the magnetic properties of natural samples. J. Geophys. Res. 105, 28461-28475, doi:10.1029/2000jb900326 (2000).

14. Egli, R., Chen, A. P., Winklhofer, M., Kodama, K. P. \& Horng, C. S. Detection of noninteracting single domain particles using first-order reversal curve diagrams. Geochem. Geophys. Geosyst. 11, Q01Z11, doi:10.1029/2009gc002916 (2010).

15. Heslop, D., Roberts, A. P. \& Chang, L. Characterizing magnetofossils from firstorder reversal curve (FORC) central ridge signatures. Geochem. Geophys. Geosyst. 15, 2170-2179, doi:10.1002/2014GC005291 (2014).

16. Roberts, A. P., Heslop, D., Zhao, X. \& Pike, C. R. Understanding fine magnetic particle systems through use of first-order reversal curve diagrams. Rev. Geophys. 52 doi:10.1002/2014RG000462 (2014).

17. Oldfield, F. Mud and magnetism: records of late Pleistocene and Holocene environmental change recorded by magnetic measurements. J. Paleolimnol. 49, 465-480, doi:10.1007/s10933-012-9648-8 (2013).

18. Verwey, E. Electronic conduction of magnetite $\left(\mathrm{Fe}_{3} \mathrm{O}_{4}\right)$ and its transition point at low temperatures. Nature 144, 327-328, doi:10.1038/144327b0 (1939).

19. Moskowitz, B. M., Frankel, R. B. \& Bazylinski, D. A. Rock magnetic criteria for the detection of biogenic magnetite. Earth Planet. Sci. Lett. 120, 283-300, doi:10.1016/ 0012-821x(93)90245-5 (1993).

20. Pan, Y. X. et al. The detection of bacterial magnetite in recent sediments of Lake Chiemsee (southern Germany). Earth Planet. Sci. Lett. 232, 109-123, doi:10.1016/ j.epsl.2005.01.006 (2005)

21. Özdemir, Ö., Dunlop, D. J. \& Moskowitz, B. M. The effect of oxidation on the Verwey transition in magnetite. Geophys. Res. Lett. 20, 1671-1674, doi:10.1029/ 93GL01483 (1993).
22. Li, J. H., Benzerara, K., Bernard, S. \& Beyssac, O. The link between biomineralization and fossilization of bacteria: Insights from field and experimental studies. Chem. Geol. 359, 49-69, doi:10.1016/ j.chemgeo.2013.09.013 (2013).

23. Bazylinski, D. A. \& Frankel, R. B. Magnetosome formation in prokaryotes. Nat Rev. Microbiol. 2, 217-230, doi:10.1038/nrmicro842 (2004).

24. Li, J. H. \& Pan, Y. X. Environmental factors affect magnetite magnetosome synthesis in Magnetospirillum magneticum AMB-1: Implications for biologically controlled mineralization. Geomicrobiol. J. 29, 362-373, doi:10.1080/ 01490451.2011 .565401 (2012)

25. Yamazaki, T. \& Shimono, T. Abundant bacterial magnetite occurrence in oxic red clay. Geology 41, 1191-1194, doi:10.1130/G34782.1 (2013)

26. Xiao, J. L., Si, B., Zhai, D. Y., Itoh, S. \& Lomtatidze, Z. Hydrology of Dali Lake in central-eastern Inner Mongolia and Holocene East Asian monsoon variability. J. Paleolimnol. 40, 519-528, doi:10.1007/s10933-007-9179-x (2008).

27. Xiao, J. L. et al. Partitioning of the grain-size components of Dali Lake core sediments: evidence for lake-level changes during the Holocene. J. Paleolimnol. 42, 249-260, doi:10.1007/s10933-008-9274-7 (2009).

28. Laskar, J. et al. A long-term numerical solution for the insolation quantities of the Earth. Astron. Astrophys. 428, 261-285, doi:10.1051/0004-6361,20041335 (2004).

29. Rea, D. K. \& Leinen, M. Asian aridity and the zonal westerlies: Late Pleistocene and Holocene record of eolian deposition in the northwest Pacific Ocean. Palaeogeogr. Palaeoclimatol. Palaeoecol. 66, 1-8, doi:10.1016/00310182(88)90076-4 (1988).

30. Bond, G. et al. A pervasive millennial-scale cycle in North Atlantic Holocene and glacial climates. Science 278, 1257-1266, doi:10.1126/science.278.5341.1257 (1997).

31. deMenocal, P. et al. Abrupt onset and termination of the African Humid Period: rapid climate responses to gradual insolation forcing. Quat. Sci. Rev. 19, 347-361, doi:10.1016/S0277-3791(99)00081-5 (2000).

32. Gasse, F. \& Van Campo, E. Abrupt post-glacial climate events in West Asia and North Africa monsoon domains. Earth Planet. Sci. Lett. 126, 435-456, doi:10.1016/0012-821X(94)90123-6 (1994).

33. deMenocal, P., Ortiz, J., Guilderson, T. \& Sarnthein, M. Coherent high-and lowlatitude climate variability during the Holocene warm period. Science 288, 2198-2202, doi:10.1126/science.288.5474.2198 (2000).

34. Haug, G. H., Hughen, K. A., Sigman, D. M., Peterson, L. C. \& Rohl, U. Southward migration of the intertropical convergence zone through the Holocene. Science 293, 1304-1308, doi:10.1126/science.1059725 (2001).

35. Wang, Y. J. et al. The Holocene Asian monsoon: Links to solar changes and North Atlantic climate. Science 308, 854-857, doi:10.1126/science.1106296 (2005).

36. Li, Z. G. Annals of Hexigten Banner (in Chinese). 547-552 (People's Press of Inner Mongolia, Hohhot, 1993).

37. Heslop, D. \& Roberts, A. P. Estimation of significance levels and confidence intervals for first-order reversal curve distributions. Geochem. Geophys. Geosyst. 13, Q12Z40, doi:10.1029/2012GC004115 (2012).

\section{Acknowledgments}

We thank Jiawei Fan, Ruilin Wen and Dayou Zhai for help during fieldwork and Yinzhao Wang for assistance with magnetic extraction. TEM analyses were performed at the Institut de Minéralogie, de Physique des Matériaux, et de Cosmochimie (IMPMC), (CNRS UMR 7590, Sorbonne Universités, MNHN, UPMC, IRD UMR 206, 75005 Paris, France). This research was supported by the NSFC grant 41330104 and the 973 program grant 2012CB821900. J.X. was supported by the 973 program grant 2010CB833400 and the NSFC grant 41130101. J.L. received support from the NSFC grant 41374004. C.D. acknowledges further support from the NSFC grant 40925012 and the CAS Bairen Program.

\section{Author contributions}

C.D., J.X., J.L., Y.P. and R.Z. designed the study. J.X. collected samples. S.L., J.L. and H.Q. conducted experiments. S.L., J.L., G.A.P., L.C., L.Y. and C.D. wrote the paper. All authors contributed to data interpretation and provided significant input to the final manuscript.

\section{Additional information}

Supplementary information accompanies this paper at http://www.nature.com/ scientificreports

Competing financial interests: The authors declare no competing financial interests.

How to cite this article: Liu, S. et al. Insolation driven biomagnetic response to the Holocene Warm Period in semi-arid East Asia. Sci. Rep. 5, 8001; DOI:10.1038/srep08001 (2015).

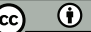

This work is licensed under a Creative Commons Attribution 4.0 International License. The images or other third party material in this article are included in the article's Creative Commons license, unless indicated otherwise in the credit line; if the material is not included under the Creative Commons license, users will need to obtain permission from the license holder in order to reproduce the material. To view a copy of this license, visit http://creativecommons.org/licenses/by/4.0/ 